Динамика клинико-функциональных показателей во взаимосвязи с изменениями иммунного гомеостаза у больных инфарктом миокарда при раннем назначении флувастатина

\author{
В.В. Белов, С.Ю. Бездольнова*, И.И. Аолгушин
}

ГОУ ВПО “Челябинская государственная медицинская академия Росздрава”. Челябинск, Россия

\title{
Dynamics of clinical, functional, and immune parameters in patients with myocardial infarction and early fluvastatin administration
}

\author{
V.V. Belov, S.Yu. Bezdol'nova*, I.I. Dolgushin \\ Chelyabinsk State Medical Academy. Chelyabinsk, Russia
}

\begin{abstract}
Цель. Определить взаимосвязь и динамику иммунологических, клинико-функциональных показателей у больных инфарктом миокарда (ИМ) при раннем назначении флувастатина.

Материал и методы. В исследовании приняли участие 129 мужчин, средний возраст 57 [42;67] лет. Из них 99 с ИМ, 30 - практически здоровые лица. Исследовались физикальные параметры, биохимические, иммунологические и функциональные показатели. Сопоставлялись группы (гр.) практически здоровых и больных; гр. принимавших флувастатин 80 мг/сут. и не принимавших его.

Результаты. У больных ИМ, имеются признаки хронического системного воспаления, подтвержденные повышенным уровнем С-реактивного белка, интерлейкина (ИЛ) $1 \beta$, ИЛ 8 , фактора некроза опухоли $\alpha$, иммуноглобулинов $\mathrm{A}$ и $\mathrm{G}$, увеличением уровня компонентов комплемента, пониженным уровнем рецепторного антагониста к ИЛ 1, сниженными уровнями CD 3, CD 4, CD 16, CD 4/CD 8 в сравнении с гр. практически здоровых лиц. Флувастатин, назначенный в первые часы после развития ИМ, уменьшает иммунологические сдвиги, признаки воспаления.

Заключение. При назначении флувастатина в первые часы развития ИМ через 2 мес отмечается достоверное снижение систолического и диастолического давления существенное повышение толерантности к физической нагрузке.
\end{abstract}

Ключевые слова: инфаркт миокарда, воспаление, флувастатин, функциональные показатели.

Aim. To assess the interrelations in the dynamics of immune, clinical, and functional parameters among patients with myocardial infarction (MI) and early fluvastatin administration.

Material and methods. The study included 129 men, aged from 42 to 67 years (mean age 57 years): 99 MI patients and 30 healthy controls. In all participants, clinical, biochemical, functional, and immune parameters were assessed, with comparisons between healthy individuals vs. MI patients, as well as between MI patients taking fluvastatin $(80 \mathrm{mg} / \mathrm{d})$ vs. MI patients not receiving this medication.

Results. In men with MI, chronic systemic inflammation was manifested in elevated levels of C-reactive protein, interleukin (IL) $1 \beta$, IL8, tumor necrosis factor $\alpha$, immunoglobulin A and G, and complement components, as well as in decreased levels of IL1 receptor antagonist, CD 3, CD 4, CD 16, and CD 4/CD 8, compared to healthy controls. Early fluvastatin administration (first post-MI hours) was associated with reduced severity of immune disturbances and systemic inflammation.

Conclusion. In MI patients, early fluvastatin administration is associated with a significant reduction in systolic and diastolic blood pressure levels, compared to controls, as well as with a substantial increase in exercise capacity at 2 months.

Key words: Myocardial infarction, inflammation, fluvastatin, functional parameters.

с Коллектив авторов, 2011

e-mail: doc-lana@mail.ru

Тел.: 8(351)772-80-22

[Белов В.В. - заведующий кафедрой внутренних болезней и военно-полевой медицины, Бездольнова С.Ю. (*контактное лицо) - аспирантка кафедры внутренних болезней и военно-полевой медицины, И.И. Долгушин - заведующий кафедрой микробиологии, вирусологии, иммунологии с курсом клинико-лабораторной диагностики]. 
Проблема лечения инфаркта миокарда (ИМ) в настоящее время остается весьма актуальной. В последние годы развивается иммунологическая концепция возникновения, прогрессирования коронарного атеросклероза и его ишемических осложнений [9].

Попытки использования иммунологических препаратов при ИМ не оправдали ожиданий. В то же время, назначение статинов для лечения различных форм ишемической болезни сердца (ИБС) дали обнадеживающие результаты, что связывают с их плейотропными эффектами [2, 5]. Дискутируются вопросы о сроках назначения статинов, целесообразности учета исходных уровней липидов. По мнению ряда авторов, важным является изучение каждого статина, особенностей его плейотропного действия во взаимосвязи с клиническими данными $[4,10]$.

Цель исследования - определить взаимосвязь и динамику иммунологических, клинико-функциональных показателей у больных ИМ при раннем назначении флувастатина.

\section{Материал и методы}

Тип исследования - открытое, рандомизированное, проспективное. В исследовании приняли участие 129 мужчин, средний возраст которых - 57 [42;67] лет. Из них 99 - с ИМ, подтвержденным данными согласно рекомендациям Всероссийского научного общества кардиологов (ВНОК) [7], 30 человек - практически здоровые лица. Госпитализации подлежали лица с длительным болевым синдромом в покое в период до 48 ч. В исследование не включали пациентов с активными воспалительными процессами, иммунопатологическими, онкологическими, эндокринными, психическими и наркологическими заболеваниями. Все пациенты, поступившие в блок интенсивной терапии, получали стандартную терапию. В момент поступления у больных ИМ оценивались жалобы, частота сердечных сокращений (ЧСС), артериальное давление (АД); определялись концентрации общего холестерина (ОХС), триглицеридов (ТГ), липопротеинов высокой плотности (ЛВП), липопротеинов низкой плотности (ЛНП), общего белка и альбуминов, аспарагиновой (АСТ) и аланиновой (АЛТ), трансаминаз креатинфосфокиназы фракция МВ (КФК-МВ), С-реактивного белка (СРБ); а также количество иммуноглобулинов (Ig) M, G, А, циркулирующих иммунных комплексов (ЦИК), уровень общей комплементарной активности (СН 50), компонентов комплемента (C) 1-5, фагоцитарная активность нейтрофилов, субпопуляции лейкоцитов (CD - 3, 4, 8, 16, 20, $95)$, уровень интерлейкинов (ИЛ) $1 \beta$, ИЛ 8 , фактора некроза опухоли $\alpha(Ф \mathrm{HO} \alpha)$, рецепторного антагониста к ИЛ 1 (РАИЛ 1).

Все больные при поступлении были рандомизированы методом случайных чисел на 2 группы (гр.): гр. (n=66) принимавших флувастатин 80 мг/сут. - гр. вмешательства (ГВ) и гр. (n=33) больных ИМ, не принимавшая флувастатин - гр. сравнения (ГС). Гр. были сопоставимы по возрасту, средним показателям АД, ЧСС, тяжести состояния по клинико-функциональным показателям. В исследование включена гр. $(\mathrm{n}=30)$ здорового контроля $(Г К)-$ мужчины 42-52 лет, проходившие комиссию на пригодность к вождению личного автотранспорта (категория В). В ГК включали лиц без жалоб и отклонений от нормы при физикальном обследовании, с нормальными показателями клинических анализов крови, мочи и без кодируемых признаков электрокардиограммы (ЭКГ) по Миннесотскому коду. В ГК однократно исследовались указанные биохимические и иммунологические показатели.

По прошествии 10 сут. всем больным ИМ выполняли эхокардиографию (ЭхоКГ). На 18-21 сут. после ИМ пациентам проводился тест 6-минутной ходьбы (т6мх), а также велоэргометрия (ВЭМ) [7]. По истечении 2 мес. после ИМ у больных вновь исследовались иммунологические и биохимические показатели, выполняли т6мх, ЭКГ. После выписки из стационара пациенты получали стандартную терапию: аспирин 100 мг/сут., метопролол 25-50 мг/сут. или конкор 5-10 мг/сут., эналаприл 10-40 мг/ сут. или лизиноприл 10-20 мг/сут. Ингибиторы ангиотензин-превращающего фермента (ИАПФ) в обеих гр. применяли $95 \%$ пациентов. Нитраты назначали лишь $5 \%$ пациентов в ГВ и 7 \% в ГС. Процедуры реваскуляризации после перенесенного ИМ не проводились.

Полученные результаты обрабатывались с помощью пакета программ "Statistica v.6.0" с использованием непараметрического метода Mann-Whitney U критерия Wilcoxon и Kruscal-Wallis. Динамику показателей $(\Delta)$ pacсчитывали как медиану разниц показателей при поступлении и при выписке. Все результаты представлены в виде Me [5 \%;95 \%]. Достоверными принимались различия при $\mathrm{p}<0,05$.

\section{Результаты и обсуждение}

При сопоставлении 2 гр. больных ИМ и ГК по иммунологическим показателям оказалось, что имеются четко выраженные признаки воспаления у лиц с ИМ по сравнению с ГК. У всех пациентов с ИМ отмечались достоверно повышенные уровни цитокинов ИЛ 8 , ИЛ $1 \beta$, ФНО $\alpha$ по сравнению с ГК (таблица 1). Концентрация противовоспалительного цитокина РАИЛ 1 у больных ИМ была ниже, по сравнению с ГК $(\mathrm{p} \leq 0,05)$. По данным исследования FRISC 1996 установлено, что в нестабильных атеросклеротических бляшках (АБ) преобладают провоспалительные цитокины [20]. Высокий уровень цитокина ИЛ $1 \beta$ в плазме крови является достоверным и независимым предиктором развития ИМ, а максимальное увеличение его концентрации связывают с летальным исходом [11]. Повышение уровня ФНО $\alpha$ у больных ИМ достоверно коррелирует с его осложненным течением или наличием выраженной сердечной недостаточности III, IV класса по Killip) $[15,16]$. Установлено, что ИЛ 8 при ИМ является важным эндогенным медиатором острой фазы ответа [8].

Концентрации СН 50 у больных ИМ и в ГК при поступлении достоверно не отличаются. СН 50 применяется для контроля потребления комплемента у пациентов при хроническом воспалении, которое может иметь место при атеросклерозе. Уровень компонентов системы комплемента в ГВ и ГС оказался достоверно выше по сравнению с ГК. 
Таблица 1

Иммунологические показатели у больных ИМ, динамика их при раннем назначении флувастатина

\begin{tabular}{|c|c|c|c|c|}
\hline \multirow[t]{3}{*}{ Иммунологические показатели } & \multicolumn{3}{|l|}{ Больные ИМ } & \multirow[t]{3}{*}{$\Gamma \mathrm{K}, \mathrm{n}=30$} \\
\hline & \multicolumn{2}{|l|}{ Гр. } & \multirow{2}{*}{$\begin{array}{l}\text { ИМ всего } \\
\mathrm{n}=99\end{array}$} & \\
\hline & $\Gamma \mathrm{B}, \mathrm{n}=66$ & $\Gamma \mathrm{C}, \mathrm{n}=33$ & & \\
\hline $\mathrm{CD} 31(\%)$ & $\begin{array}{l}30,00 \\
{[14,00 ; 56,00]}\end{array}$ & $\begin{array}{l}46,00 \\
{[26,00 ; 56,00]}\end{array}$ & $\begin{array}{l}38,00 \\
{[16,00 ; 56,00]}\end{array}$ & $\begin{array}{l}52,06 \\
{[30,00 ; 60,00]^{\wedge}}\end{array}$ \\
\hline CD3 2(\%) & $\begin{array}{l}36,00 \\
{[24,00 ; 55,80] \text { * }}\end{array}$ & $\begin{array}{l}30,50 \\
{[28,00 ; 61,00] \text { * }}\end{array}$ & - & - \\
\hline$\Delta \mathrm{CD} 3(\%)$ & $\begin{array}{l}-6,00 \\
{[-27,80 ; 28,00]^{*}}\end{array}$ & $\begin{array}{l}11,50 \\
{[-24,00 ; 28,00] *}\end{array}$ & - & - \\
\hline CD4 1(\%) & $\begin{array}{l}18,00 \\
{[10,00 ; 44,00]}\end{array}$ & $\begin{array}{l}31,00 \\
{[20,00 ; 37,00]}\end{array}$ & $\begin{array}{l}21,5 \\
{[12,00 ; 37,00]}\end{array}$ & $\begin{array}{l}31,63 \\
{[15,00 ; 48,00]^{\wedge}}\end{array}$ \\
\hline CD4 2(\%) & $\begin{array}{l}24,00 \\
{[18,00 ; 20,00]}\end{array}$ & $26,00[20,00 ; 40,00]$ & - & - \\
\hline$\Delta \mathrm{CD} 4(\%)$ & $\begin{array}{l}-5,00 \\
{[-22,85 ; 26,00]}\end{array}$ & $\begin{array}{l}4,50 \\
{[-16,00 ; 11,00]}\end{array}$ & - & - \\
\hline CD $81(\%)$ & $\begin{array}{l}20,00 \\
{[10,00 ; 32,00]}\end{array}$ & $\begin{array}{l}28,00 \\
{[20,95 ; 35,00]}\end{array}$ & $\begin{array}{l}24,00 \\
{[10,00 ; 35,00]}\end{array}$ & $\begin{array}{l}24,42 \\
{[12,00 ; 37,00]}\end{array}$ \\
\hline CD8 2(\%) & $\begin{array}{l}21,00 \\
{[12,00 ; 27,60] *}\end{array}$ & $\begin{array}{l}20,50 \\
{[1,60 ; 30,00]^{*}}\end{array}$ & - & - \\
\hline$\Delta \mathrm{CD} 8(\%)$ & $\begin{array}{l}-2,00 \\
{[-16,80 ; 17,60]^{*}}\end{array}$ & $\begin{array}{l}7,50 \\
{[-3,70 ; 33,40] *}\end{array}$ & - & - \\
\hline $\mathrm{CD} 4 / \mathrm{CD} 81$ & $1,10[0,7 ; 1,83]$ & $1,1[0,8 ; 1,3]$ & $1,1[0,7 ; 1,6]$ & $1,63[0,81 ; 2,47]^{\wedge}$ \\
\hline $\mathrm{CD} 4 / \mathrm{CD} 82$ & $\begin{array}{l}1,10 \\
{[0,63 ; 1,85]^{*}}\end{array}$ & $1,3[1,1 ; 1,6]^{*}$ & - & - \\
\hline$\Delta \mathrm{CD} 4 / \mathrm{CD} 8$ & $\begin{array}{l}0,00 \\
{[-0,95 ; 1,40]^{*}}\end{array}$ & $\begin{array}{l}-0,40 \\
{[-0,60 ; 0,07]^{*}}\end{array}$ & - & - \\
\hline CD16 1(\%) & $\begin{array}{l}14,00 \\
{[6,00 ; 32,00]}\end{array}$ & $\begin{array}{l}17,00 \\
{[10,00 ; 26,00]}\end{array}$ & $\begin{array}{l}14,00 \\
{[6,00 ; 32,00]}\end{array}$ & $\begin{array}{l}18,00 \\
{[9,00 ; 28,00]^{\wedge}}\end{array}$ \\
\hline $\mathrm{CD} 162(\%)$ & $\begin{array}{l}16,00 \\
{[10,00 ; 30,00]}\end{array}$ & $\begin{array}{l}14,00 \\
{[10,00 ; 22,00]}\end{array}$ & - & - \\
\hline$\Delta \mathrm{CD} 16(\%)$ & $\begin{array}{l}-3,00 \\
{[-20,00 ; 19,00]}\end{array}$ & $\begin{array}{l}4,50 \\
{[-7,00 ; 7,00]}\end{array}$ & - & - \\
\hline CD20 1(\%) & $\begin{array}{l}16,00 \\
{[7,00 ; 30,00]}\end{array}$ & $\begin{array}{l}14,00 \\
{[7,00 ; 32,00]}\end{array}$ & $\begin{array}{l}16,00 \\
{[7,00 ; 32,00]}\end{array}$ & $\begin{array}{l}17,00 \\
{[8,00 ; 25,00]}\end{array}$ \\
\hline CD20 2(\%) & $\begin{array}{l}16,00 \\
{[10,00 ; 21,00]}\end{array}$ & $\begin{array}{l}14 \\
{[13,00 ; 26,00]}\end{array}$ & - & - \\
\hline$\Delta \mathrm{CD} 20(\%)$ & $\begin{array}{l}1,00 \\
{[-10,00 ; 13,80]}\end{array}$ & $\begin{array}{l}-4,50 \\
{[-7,00 ; 7,05]}\end{array}$ & - & - \\
\hline CD95 1(\%) & $\begin{array}{l}18,00 \\
{[7,00 ; 38,00]}\end{array}$ & $\begin{array}{l}13,00 \\
{[10,00 ; 20,00]}\end{array}$ & $\begin{array}{l}13,00 \\
{[7,00 ; 34,00]}\end{array}$ & $\begin{array}{l}6,00 \\
{[5,00 ; 8,00]^{\wedge}}\end{array}$ \\
\hline CD952(\%) & $\begin{array}{l}16,00 \\
{[9,00 ; 27,00]}\end{array}$ & $\begin{array}{l}16,00 \\
{[6,00 ; 26,00]}\end{array}$ & - & - \\
\hline$\Delta \mathrm{CD} 95(\%)$ & $\begin{array}{l}-1,00 \\
{[-13,80 ; 24,00]}\end{array}$ & $\begin{array}{l}0,50 \\
{[-16,00 ; 13,00]}\end{array}$ & - & - \\
\hline $\begin{array}{l}\text { CH } 501 \\
\text { (y.e.) }\end{array}$ & $\begin{array}{l}60,20 \\
{[47,40 ; 73,50]}\end{array}$ & $\begin{array}{l}58,10 \\
{[51,70 ; 70,30]}\end{array}$ & $\begin{array}{l}58,11 \\
{[47,84 ; 73,32]}\end{array}$ & $\begin{array}{l}57,31 \\
{[28,50 ; 86,40]}\end{array}$ \\
\hline $\begin{array}{l}\text { CH } 502 \\
\text { (y.e.) }\end{array}$ & $\begin{array}{l}56,30 \\
{[38,40 ; 77,70] \text { * }}\end{array}$ & $\begin{array}{l}62,10 \\
{[54,30 ; 74,80]^{*}}\end{array}$ & - & - \\
\hline$\Delta \mathrm{CH} 50$ (y.e.) & $\begin{array}{l}4,30 \\
{[-18,20 ; 32,70] *}\end{array}$ & $\begin{array}{l}-3,00 \\
{[-12,40 ; 3,80]}\end{array}$ & - & - \\
\hline C 11 (y.e.) & $\begin{array}{l}90,30 \\
{[64,21 ; 165,00]}\end{array}$ & $\begin{array}{l}91,40 \\
{[81,10 ; 165,00]}\end{array}$ & $90,8[65,5 ; 165,12]^{\wedge}$ & $\begin{array}{l}69,69 \\
{[34,61 ; 106,05]^{\wedge}}\end{array}$ \\
\hline C 12 (y.e.) & $\begin{array}{l}102,50 \\
{[62,60 ; 129,60]}\end{array}$ & $\begin{array}{l}102,70 \\
{[96,20 ; 139,30]}\end{array}$ & - & - \\
\hline$\Delta \mathrm{C} 1$ (y.e.) & $\begin{array}{l}-12,70 \\
{[-62,12 ; 63,80]}\end{array}$ & $\begin{array}{l}-10 \\
{[-38,32 ; 67,05]}\end{array}$ & - & - \\
\hline C 2 1(y.e.) & $\begin{array}{l}85,20 \\
{[62,10 ; 141,30]}\end{array}$ & $\begin{array}{l}86,90 \\
{[80,10 ; 141,30]}\end{array}$ & $\begin{array}{l}85,23 \\
{[66,17 ; 141,36]^{\wedge}}\end{array}$ & $\begin{array}{l}52,66 \\
{[26,01 ; 79,69]^{\wedge}}\end{array}$ \\
\hline C 22 (y.e.) & $\begin{array}{l}85,20 \\
{[75,10 ; 97,10]}\end{array}$ & $\begin{array}{l}85,45 \\
{[75,10 ; 93,10]}\end{array}$ & - & - \\
\hline
\end{tabular}


Продолжение таблицы 1

\begin{tabular}{|c|c|c|c|c|}
\hline$\Delta \mathrm{C} 2$ (y.e.) & $\begin{array}{l}2,72 \\
{[-19,00 ; 52,80]}\end{array}$ & $\begin{array}{l}3,80 \\
{[-9,31 ; 59,05]}\end{array}$ & - & - \\
\hline C 3 1(y.e.) & $\begin{array}{l}88,10 \\
{[38,10 ; 126,80]}\end{array}$ & $\begin{array}{l}88,10 \\
{[78,20 ; 124,10]}\end{array}$ & $\begin{array}{l}88,1 \\
{[38,26 ; 124,16]^{\wedge}}\end{array}$ & $\begin{array}{l}66,22 \\
{[32,68 ; 100,60]^{\wedge}}\end{array}$ \\
\hline С 32 (y.e.) & $\begin{array}{l}93,10 \\
{[79,10 ; 135,90]}\end{array}$ & $\begin{array}{l}91,85 \\
{[79,10 ; 97,90]}\end{array}$ & - & - \\
\hline$\Delta$ C 3 (y.e.) & $\begin{array}{l}-5,90 \\
{[-57,00 ; 32,92]}\end{array}$ & $\begin{array}{l}-4,35 \\
{[-32,02 ; 32,96]}\end{array}$ & - & - \\
\hline C 4 1(y.e.) & $\begin{array}{l}78,50 \\
{[65,10 ; 112,10]}\end{array}$ & $\begin{array}{l}73,55 \\
{[65,10 ; 112,90]}\end{array}$ & $\begin{array}{l}78,54 \\
{[65,22 ; 112,96]^{\wedge}}\end{array}$ & $\begin{array}{l}71,14 \\
{[35,12 ; 108,03]^{\wedge}}\end{array}$ \\
\hline C 42 (y.e.) & $\begin{array}{l}78,87 \\
{[65,10 ; 117,40]}\end{array}$ & $\begin{array}{l}76,61 \\
{[65,10 ; 101,50]}\end{array}$ & - & - \\
\hline$\Delta$ C 4 (y.e.) & $\begin{array}{l}-3,22 \\
{[-35,30 ; 38,92]}\end{array}$ & $\begin{array}{l}-2,56 \\
{[-35,30 ; 38,92]}\end{array}$ & - & - \\
\hline C 5 1(y.e.) & $\begin{array}{l}81,70 \\
{[68,20 ; 140,70]}\end{array}$ & $\begin{array}{l}80,10 \\
{[2,30 ; 119,80]}\end{array}$ & $\begin{array}{l}81,11 \\
{[68,25 ; 119,84]^{\wedge}}\end{array}$ & $\begin{array}{l}69,89 \\
{[34,58 ; 105,92]^{\wedge}}\end{array}$ \\
\hline C 52 (y.e.) & $\begin{array}{l}100,90 \\
{[84,70 ; 123,30]}\end{array}$ & $\begin{array}{l}103,60 \\
{[85,10 ; 123,30]}\end{array}$ & - & - \\
\hline$\Delta$ C 5 (y.e.) & $\begin{array}{l}-11,60 \\
{[-84,50 ; 39,80]}\end{array}$ & $\begin{array}{l}-26,20 \\
{[-99,55 ; 24,43]}\end{array}$ & - & - \\
\hline Ig A 1 (г/л) & $\begin{array}{l}2,00 \\
{[0,82 ; 3,22]}\end{array}$ & $\begin{array}{l}1,80 \\
{[1,60 ; 2,80]}\end{array}$ & $1,95[0,85 ; 3,13]$ & $1,50[0,74 ; 2,28]^{\wedge}$ \\
\hline Ig A 2 (г/л) & $\begin{array}{l}1,85 \\
{[1,34 ; 2,98] *}\end{array}$ & $\begin{array}{l}2,31 \\
{[1,93 ; 2,50] \text { * }}\end{array}$ & - & - \\
\hline$\Delta \operatorname{Ig} \mathrm{A}$ (г/л) & $\begin{array}{l}0,00 \\
{[-1,05 ; 1,46]}\end{array}$ & $\begin{array}{l}-0,43 \\
{[-0,85 ; 0,54]}\end{array}$ & - & - \\
\hline Ig M 1 (г/л) & $\begin{array}{l}1,05 \\
{[0,65 ; 2,20]}\end{array}$ & $\begin{array}{l}1,05 \\
{[0,45 ; 1,30]}\end{array}$ & $1,05[0,65 ; 1,95]$ & $1,15[0,57 ; 1,75]$ \\
\hline Ig M 2 (г/л) & $1,25[0,75 ; 1,80]$ & $\begin{array}{l}1,20 \\
{[0,95 ; 1,50]}\end{array}$ & - & - \\
\hline$\Delta$ Ig M, г/л & $\begin{array}{l}0,00 \\
{[-0,95 ; 1,08]}\end{array}$ & $\begin{array}{l}0,10 \\
{[-0,67 ; 0,40]}\end{array}$ & - & - \\
\hline Ig G 1(г/л) & $10,00[6,00 ; 12,00]$ & $10,60[7,60 ; 12,00]$ & $10,15[6,05 ; 12,06]$ & $8,06[4,27 ; 19,97]^{\wedge}$ \\
\hline Ig G 2 (г/л) & $10,10[4,70 ; 14,70]$ & $11,49[7,87 ; 14,50]$ & - & - \\
\hline$\Delta \operatorname{Ig} G$ (г/л) & $\begin{array}{l}0,00 \\
{[-5,09 ; 5,60]}\end{array}$ & $\begin{array}{l}-0,89 \\
{[-3,90 ;-0,15]}\end{array}$ & - & - \\
\hline $\begin{array}{l}\text { ИЛ } 81 \\
\text { (пг/мл) }\end{array}$ & $\begin{array}{l}42,17 \\
{[26,00 ; 203,27]^{*}}\end{array}$ & $\begin{array}{l}40,81 \\
{[18,94 ; 63,03]^{*}}\end{array}$ & $42,17[18,34 ; 182,34]$ & $15,9[7,51 ; 25,17]^{\wedge}$ \\
\hline $\begin{array}{l}\text { ИЛ } 82 \\
\text { (пг/мл) }\end{array}$ & $65,40[31,99 ; 151,75]^{*}$ & $\begin{array}{l}101,00 \\
{[16,16 ; 153,16]^{*}}\end{array}$ & - & - \\
\hline$\Delta$ ИЛ 8 (пг/мл) & $\begin{array}{l}-6,35 \\
{[-101,86 ; 152,93]^{*}}\end{array}$ & $\begin{array}{l}-45,67 \\
{[-134,22 ; 24,66]^{*}}\end{array}$ & - & - \\
\hline ИЛ $1 \beta 1$ (пг/мл) & $51,10[13,68 ; 310,22]^{*}$ & $15,03[5,00 ; 40,15]^{*}$ & $34,85[5,71 ; 169,65]$ & $10,7[5,29 ; 16,24]^{\wedge}$ \\
\hline ИЛ $1 \beta 2$ (пг/мл) & $38,26[13,88 ; 213,50]^{*}$ & $29,66[3,31 ; 51,10]^{*}$ & - & - \\
\hline$\Delta$ ИЛ $1 \beta$ (пг/мл) & $\begin{array}{l}5,85 \\
{[-63,20 ; 74,44]^{*}}\end{array}$ & $\begin{array}{l}-1,86 \\
{[-46,10 ; 2,40]^{*}}\end{array}$ & - & - \\
\hline ФНО $\alpha 1$ (пг/мл) & $329,6[206,4 ; 1566,8]$ & $\begin{array}{l}267,1 \\
{[233,2 ; 301,6]}\end{array}$ & $\begin{array}{l}301,4 \\
{[232,97 ; 1006,82]}\end{array}$ & $134,7[59,42 ; 225,83]^{\wedge}$ \\
\hline ФНО $\alpha 1$ (пг/мл) & $336,2[192,1 ; 1050,9]$ & $212,4[21,6 ; 1047,5]$ & - & - \\
\hline$\Delta$ ФНО $\alpha$ (пг/мл) & $7[-1026,7 ; 2063,1]$ & $\begin{array}{l}21,4 \\
{[-746,3 ; 260,5]}\end{array}$ & - & - \\
\hline РАИЛ 11 (пг/мл) & $\begin{array}{l}157,90 \\
{[83,33 ; 1808,40]}\end{array}$ & $\begin{array}{l}131,94 \\
{[101,39 ; 309,96]}\end{array}$ & $\begin{array}{l}148,31 \\
{[86,11 ; 1216,94]}\end{array}$ & $655,30[299 ; 1067,44]^{\wedge}$ \\
\hline РАИЛ 12 (пг/мл) & $\begin{array}{l}98,24 \\
{[41,67 ; 1086,73]^{*}}\end{array}$ & $\begin{array}{l}111,11 \\
{[6,94 ; 638,49] \text { * }}\end{array}$ & - & - \\
\hline$\Delta$ РАИЛ 1 (пг/мЛ) & $\begin{array}{l}68,06 \\
{[-202,70 ; 598,85]^{*}}\end{array}$ & $\begin{array}{l}31,95 \\
{[-328,53 ; 106,95]^{*}}\end{array}$ & - & - \\
\hline
\end{tabular}


Таблица 2

Динамика СРБ у больных ИМ на фоне лечения флувастатином в сравнении с ГК

\begin{tabular}{|c|c|c|c|c|}
\hline \multirow[t]{3}{*}{ Концентрация СРБ } & \multicolumn{3}{|c|}{ Больные ИМ } & \multirow{3}{*}{$\begin{array}{l}\Gamma K \\
n=30\end{array}$} \\
\hline & \multicolumn{2}{|c|}{ Гр. } & \multirow{2}{*}{$\begin{array}{l}\text { ИМ всего } \\
\mathrm{n}=99\end{array}$} & \\
\hline & $\begin{array}{l}\Gamma \mathrm{B} \\
\mathrm{n}=66\end{array}$ & $\begin{array}{l}\Gamma \mathrm{C} \\
\mathrm{n}=33\end{array}$ & & \\
\hline СРБ1, мг/л & $16,7[5,9 ; 39,4]$ & $\begin{array}{l}13,4 \\
{[8,9 ; 32,1]}\end{array}$ & $\begin{array}{l}l 15,05 \\
{[7,4 ; 35,75]^{\wedge}}\end{array}$ & $\begin{array}{l}2,67 \\
{[1,99 ; 3,01]^{\wedge}}\end{array}$ \\
\hline СРБ2, мг/л & $4,8[2,7 ; 6,0]^{*}$ & $5,2[4,2 ; 5,6]^{*}$ & - & - \\
\hline$\Delta$ СРБ, мг/л & $11,6[1,3 ; 33,9]^{*}$ & $8,9[3,3 ; 26,6]^{*}$ & - & - \\
\hline
\end{tabular}

Уровни АД у больных ИМ в ГВ и ГК в сравнении с ГС

\begin{tabular}{|c|c|c|c|c|}
\hline \multirow{3}{*}{ Показатель АД } & \multicolumn{3}{|c|}{ Больные ИМ } & \multirow{3}{*}{$\begin{array}{l}\Gamma K \\
n=30\end{array}$} \\
\hline & \multicolumn{2}{|c|}{ Гр. } & \multirow{2}{*}{$\begin{array}{l}\text { ИМ всего } \\
\mathrm{n}=99\end{array}$} & \\
\hline & $\begin{array}{l}\Gamma \mathrm{B} \\
\mathrm{n}=66\end{array}$ & $\begin{array}{l}\Gamma \mathrm{C} \\
\mathrm{n}=33\end{array}$ & & \\
\hline САД1, мм рт.ст. & $130[90 ; 180]$ & $140[100 ; 150]$ & $135[95 ; 165]^{\wedge}$ & $115[110 ; 125]^{\wedge}$ \\
\hline САД2, мм рт.ст. & $110[110 ; 140] *$ & $120[100 ; 120]^{*}$ & - & - \\
\hline АСАД, мм рт.ст. & $20[-20 ; 30] *$ & $10[0,0 ; 30]^{*}$ & - & - \\
\hline ДАД1, мм рт.ст. & $90[50 ; 110]$ * & $80[60 ; 90]$ * & $89[55 ; 100]^{\wedge}$ & $65[60 ; 80]^{\wedge}$ \\
\hline ДАД2, мм рт.ст. & $80[60 ; 80]$ * & $70[60 ; 80]^{*}$ & - & - \\
\hline АДАД, мм рт.ст. & $10[-30,0 ; 40] *$ & $20[-20 ; 20,0] *$ & - & - \\
\hline
\end{tabular}

Примечание: ${ }^{1-}$ при поступлении; ${ }^{2-}$ через 2 мес. после ИМ; ${ }^{*}-\mathrm{p} \leq 0,05$ при сравнении ГВ и ГС; ${ }^{\wedge}-\mathrm{p} \leq 0,05$ при сравнении больных и здоровых.

Показатели клеточного иммунитета были достоверно ниже у больных ИМ (CD3, CD4, CD16) по сравнению с ГК. В ГВ и ГС отмечен достоверно более низкий хелперно-супрессорный коэффициент (CD4/CD8). CD 95 (рецептор апоптоза) у больных ИМ достоверно выше, чем в ГК. Снижение клеточного иммунитета, может быть обусловлено воздействием на Т- и В-лимфоциты высоких доз цитокинов, которые участвуют в ингибировании Т-клеточной активности и могут указывать на активацию воспаления [13]. Повышение CD 95 при ИМ можно считать проявлением нарушения адекватного ответа оксидазной микробицидной системы фагоцитов на нагрузку антигеном и неадекватного реагирования нейтрофилов на воспалительный процесс с резким укорочением срока их жизни [8]. В литературе имеются сведения о том, что при ИМ количество лейкоцитов, экспрессирующих CD95, достоверно возрастает уже в 1-е сут. заболевания [14].

При исследовании гуморального звена иммунитета оказалось, что у больных ИМ отмечался достоверно более высокий уровень Ig A и Ig G, чем в ГК (таблица 1).

С-реактивный белок (СРБ) является рутинным и наиболее распространенным маркером воспаления. В настояшем исследовании оказалось, что СРБ достоверно выше у лиц с ИМ, чем в ГК (таблица 2).

В начале развития ИМ СРБ активирует макрофаги, индуцирует хемотаксис. В дальнейшем вышеуказанный белок ингибирует хемотаксис, дегрануляцию тучных клеток, фагоцитоз и проявляет иммуносупрессивное действие. СРБ способствует удалению фрагментов поврежденных клеток и продуктов их распада за счет связывания с ЛНП и липопротеидов очень низкой плотности (ЛОНП) [19,20]. Было показано, что развитие ИМ влечет за собой возникновение системной и локальной воспалительной реакции, активации острофазовых белков, СРБ. Системные проявления этих процессов выражаются в развитии лейкоцитоза, повышении концентрации белков острой фазы, антител [1,25].

Данные, представленные в таблице 3, показывают, что исходно уровень систолического артериального давления (САД) и диастолического АД (ДАД) оказался достоверно выше у больных ИМ, чем в ГК.

При сопоставлении ГВ и ГС оказалось, что по прошествии 2 мес. от начала заболевания наблюдается положительная динамика ряда иммунологических показателей в обеих гр. больных ИМ, но более выраженная среди лиц из ГВ. Уровень ИЛ 8 в динамике достоверно повышается в обеих гр. больных, однако, в ГВ это повышение менее выраженное, и через 2 мес. приема статина концентрация ИЛ 8 оказалась достоверно ниже, чем ГС. В ГВ уровень ИЛ $1 \beta$ изначально был более высоким, и через 2 мес. достоверно уменьшился у лиц, принимавших флувастатин (таблица 1). В динамике получено снижение концентрации 
Функциональные показатели в гр. больных ИМ в зависимости от лечения флувастатином

\begin{tabular}{lll}
\hline Функциональные показатели & \multicolumn{2}{c}{ Больные ИМ, } \\
\cline { 2 - 3 } & ГВ, $\mathrm{n}=66$ & \multicolumn{1}{c}{$\mathrm{n}=33$} \\
\hline Т6мх1, м & $289,00[175,80 ; 386,40]^{*}$ & $321,00[297,00 ; 371,00]^{*}$ \\
т6мх2, м & $398,00[236,80 ; 547,00]^{*}$ & $431,00[387,00 ; 455,00]^{*}$ \\
$\Delta$ т6мх, м & $38,60[2,37 ; 83,64]^{*}$ & $30,30[16,17 ; 46,91] *$ \\
ВЭМ, Вт. & $30[25 ; 125]^{*}$ & $25[25 ; 50]^{*}$ \\
\hline
\end{tabular}

Примечание: ${ }^{1-}$ при поступлении; ${ }^{2-}$ через 2 мес. после ИМ; ${ }^{*}-\mathrm{p} \leq 0,05$ при сравнении ГВ и ГС.

противовоспалительного цитокина РАИЛ 1 в обеих гр. больных ИМ, но через 2 мес. лечения флувастатином уровень РАИЛ 1 оказался достоверно ниже в ГВ, чем в ГС.

В ГВ через 2 мес. произошло снижение уровня СН 50, а в ГС - повышение (таблица 1). Различие в сравниваемых гр. достигло достоверных значений. Повышение уровня СН 50 свидетельствует об активации системы комплемента по классическому пути. Назначение флувастатина блокирует процесс активации СН 50, который нарастает ко 2 мес. наблюдения, что дает основание полагать целесообразность длительного назначения препарата при ИМ. При исследовании компонентов системы комплемента в гр. больных ИМ, достоверных различий в ГВ и ГС не получено.

Применение флувастатина с первых ч от развития ИМ сопровождается достоверным повышением уровней CD3 и CD8-клеток через 2 мес., в то время как в ГС они достоверно уменьшаются, что, вероятно, связано с разнонаправленной динамикой концентраций цитокинов в сравниваемых гр. Аналогичная тенденция наблюдается и по другим субпопуляциям лимфоцитов (таблица 1). В ГВ по сравнению с ГС имеется тенденция к увеличению уровня CD 16 - маркеров естественных киллеров. Обнаружена тенденция к снижению CD 95 рецепторов через 2 мес. у лиц, принимавших флувастатин (таблица 1).

При сопоставлении гр. больных ИМ оказалось, что через 2 мес. в ГВ отмечалось уменьшение $\mathrm{Ig}$ A, тогда как у лиц из ГС он увеличился $(\mathrm{p} \leq 0,05)$ (таблица 1). Динамика Ig G в ГВ имела такую же тенденцию, но разница в гр. больных ИМ оказалась недостоверной.

Уровень СРБ при сравнении ГВ и ГС достоверно уменьшается в обеих гр., однако в ГВ снижение было более выраженным (p $\leq 0,05)$ (таблица 2).

При сравнении двух гр. больных ИМ оказалось, что снижение среднего уровня САД и ДАД в ГВ было достоверно более выраженным, чем в ГС (таблица 3), что может быть связано с плейотропным эффектом статинов в нормализации эндотелиальной дисфункции и ингибировании вазоконстрикции [6, 12]. Некоторые авторы первые сут., мес. действия статинов называют “триумфом плейотропных влияний на эндотелий” [2].
Среди больных ГВ и ГС выявлено различие в уровне толерантности к физической нагрузке (ТФН), что проявлялось более высокими показателями при ВЭМ и увеличением дистанции при проведении т6мх через 2 мес. в ГВ (p $\leq 0,05)$ (таблица 4). Полученные данные можно объяснить с позиции противовоспалительных свойств статинов и их положительных эффектов у больных с ХCH $[3,22]$.

Таким образом, полученные данные свидетельствуют об активном воспалении при ИМ, тесной взаимосвязи иммунологических реакций и клинико-функциональных данных. Назначение флувастатина 80 мг в первые сут от развития ИМ позволяет уменьшить хроническое воспаление, стабилизировать АД и увеличить ТФН. В исследованиях HPS (Heart Protection Study), в которых использовался симвастатин, PROVE-IT-TIMI (Pravastatin or Atorvastatin Evaluation and Infection Therapy Thrombolysis in Myocardial Infarction 22 Investigators) - правастатин, MIRACL (Myocardial Ischemia Reduction with Aggressive Cholesterol Lowering), GREACE (The GREek Atorvastatin and Coronary heart disease evaluation) - аторвастатин, убедительно показана эффективность указанных статинов при ОКС, включая ИМ. Положительный эффект статинов, применяемых с первых дней ОКС, связывают с их противовоспалительным действием [17, 18,21,24]. Вместе с тем в исследовании FLORIDA (Fluvastatin On Risk Diminishment after Acute myocardial infarction) лечение флувастатином, назначенным в первые 14 сут. ИМ, не сопровождалось существенными различиями в частоте летального исхода, возникновения коронарных событий в течение года в сравнении с плацебо [14,23]. Полученные результаты свидетельствуют о достоверном снижении воспалительного потенциала при назначении флувастатина, что ассоциировалось с достоверными положительными клинико-функциональными изменениями в течение первых 2 мес. после ИМ.

\section{Выводы}

У мужчин, больных ИМ, имеются признаки хронического системного воспаления, подтвержденные повышенным уровнем СРБ, ИЛ $1 \beta$, ИЛ 8 , ФНО $\alpha$, иммуноглобулинов А и $\mathrm{G}$, увеличением уровня компонентов комплемента, пониженным уровнем рецепторного антагониста к ИЛ 1, снижен- 
ными уровнями $\mathrm{CD} 3, \mathrm{CD} 4, \mathrm{CD} 16, \mathrm{CD} 4 / \mathrm{CD}$ 8 в сравнении с ГК.

Флувастатин, назначенный в первые ч после развития ИМ, уменьшает указанные иммунологические реакции, признаки воспаления.

При назначении флувастатина в первые ч развития ИМ через 2 мес. отмечается достоверное сни-

\section{Литература}

1. Алешкин В.А, Новикова Л.И., Мотов А.Г. и др. Белки острой фазы и их клиническое значение. Клин мед 1988; 8: 39-48.

2. Аронов Д.М. Каскад терапевтических эффектов статинов. Кардиология 2004; 44(10): 85-94.

3. Бейтуганов А.А., Абрамян А.А., Рылова А.К. Противовоспалительные и нефропротективные эффекты симвастатина у больных с ХСН и СД 2 типа. Серд недостат 2007; 8 (40): 81-3.

4. Беленков Ю.Н., Сергиенко И.В., Лякишев А.А., и др. Статины в современной кардиологической практике. М.: ФГУ РКНПК Росздрава 2007; 63 с.

5. Грацианский Н.А. Статины как противовоспалительные средства. Кардиология 2001;41(12): 14-26.

6. Джаиани Н.А., Ильина Е. В., Терещенко С.Н. Современные аспекты применения статинов при остром инфаркте миокарда. Сердце 2007; 6(34): 85-8.

7. Диагностика и лечение больных острым инфарктом миокарда с подъемом сегмента ST электрокардиограммы. Российские рекомендации. Приложение к журналу “Кардиоваск тер профил 2007; 6(8): 1-66.

8. Колесникова Н.В., Дабижева А.Н., Каде А.Х и др. Активационные маркеры нейтрофильных гранулоцитов при инфаркте миокарда. TERRA MEDICA nova 2004; 9: 66-8.

9. Нагорнев В.А., Зота Е.Г. Цитокины, иммунное воспаление и атерогенез. Успехи соврем биол 1996; 2 (3): 320-31.

10. Национальные рекомендации ВНОК и ОССН по диагностике и лечению ХСН (третий пересмотр). Серд недостат 2009; 10(2): 64-102.

11. Павликова Е.П., Мерай И.А. Клиническое значение интерлейкина-6 и фактора некроза опухоли- $\alpha$ при ишемической болезни. Кардиология 2003; 8: 68-71.

12. СусековА.В., Творогова М.Г., Суркова Е.В. идр. Флувастатин при лечении гиперлипопротеидемии у больных инсулиннезависимым сахарным диабетом. Кардиология 1998; 3 : 33-6.

13. Рабсон А., Ройт А., Делвз П. Основы медицинской иммунологии. Пер. с англ. Л. А. Певницкого. М.: БИНОМ 2006; $320 \mathrm{c}$.

14. Терещенко С.Н., Бармотин Г.В., Соколовская А.А. и др. Апоптоз и иммунный статус больных острым инфарктом миокарда и сердечной недостаточностью. Успехи клин иммун аллерг 2001; 1: 179-90. жение САД и ДАД по сравнению с ГС, существенное повышение ТФН.

Назначение флувастатина в дозе 80 мг/сут. в первые ч ИМ и далее в течение 2 мес. способствует нормализации иммунологического гомеостаза и улучшает клиническое течение заболевания.

15. Чазов Е.И. К вопросу об атеротромботической болезни. Кардиология 2001; 41(4): 4-7.

16. Arbustim E, Grasso M, Diegoli M. Coronary atherosclerotic plaques with and without thrombus in ischemic heart syndromes: a morphologic, immunogistochemical, and biochemical study. Am J Cardiology 1999; 68(7): 36-50.

17. Athyros VG, Papgeorgiou AA, Mercouris BR, et al. Treatment with atorvastatin to the national Cholesterol Education Programm Goal versus "Usual" Care inn Secondary Coronary Heart Disease Prevention. The GREek Atorvastatin and Coronary -heart disease evaluation (GREACE) Study. Current Medical Research and Opinion 2002; 18(4): 220-8.

18. Cannon CP, Braunwald E, McCabe $\mathrm{CH}$, et al. Pravastatin or Atorvastatin Evaluation and Infection Therapy - Thrombolysis in Myocardial Infarction 22 Investigators (PROVE IT - TIMI 22). Comparison of Intensive and Moderate Lipid Lowering with Statins after Acute Coronary Syndromes. N Eng J Med 2004; 350: 1495-504.

19. De Beer FC, Hind CRK, Fox KM, et al. Measurement of serum $\mathrm{C}$-reactive protein concentration in myocardial ischemia and infarction. Br Heart J 1982; 47: 239-43.

20. FRISC Study group. Low molecular weight heparin during Instability in Coronary Artery Disease. Fragmin during instability in coronary artery disease. Lancet 1996; 347: 561-8.

21. Heart Protection Study Collaborative Group. MRC/BHF Heart Protection Study of cholesterol lowering with simvastatin in 20536 highrisk patients: a randomized placebocontrolled trial. Lancet 2002; 360: 7-22.

22. Horwich TB, MacLellan WR, Fonarow GC. Statin therapy is associated with improved survival in ischemic and non- ischemic heart failure. JACC 2004; 43(4): 642-8.

23. Liem A, van Boven AJ, Withagen AP, et al. Fruvastatin in acute myocardial infarction: effects on early and late ischaemia events: the FLORIDA trail. Circulation 2000; 102: 2672-d.18.

24. Schwartz GG, Olsson AG, Ezekowitz MD, et al. Myocardial Ischemia Reduction with Aggressive Cholesterol Lowering (MIRACLE) study Investigators. Effects of Atorvastatin on early recurrent ischemic events in acute coronary syndromes: the MIRACLE study: a randomized controlled trial. JAMA 2001; 285(13): 1711-8.

25. Smith SJ, Bos G, Essvild R. Acute - phase proteins from the liver and enzymes from myocardial infarction, a quantitative relationship. Clin Chem Acta 1977; 81: 75-85. 